\title{
Vibrational Analysis of a Metallic Column Submitted to Mechanical Axial Load and Fire Exposure
}

\author{
A.N. Ndoukouo ${ }^{(D)} *$, J. Metsebo ${ }^{(D)} \alpha, 1$ and J.M Njankouo ${ }^{i D} \mathcal{S}$ \\ *Department of Architecture and Engineering Arts, Fine Arts Institute, P.O Box 31 Foumban, University of Dschang, Cameroon, ${ }^{\alpha}$ Department of Hydraulics \\ and Water Management, National Advanced School of Engineering, University of Maroua, P.O Box 46 Maroua, Cameroon, ${ }^{\S}$ Department of Civil Engineering \\ and Urban Planning of National Advanced School of Engineering, University of Yaounde I, P.O Box 8390 Yaounde, Cameroon.
}

ABSTRACT Vibrational behavior and structural failure of a metallic beam submitted to simultaneous action KEYWORDS of axial load and fire exposure are investigated. Analyses are made at ambient conditions and for two types of fire, ISO 834 fire and parametric fire. Vibrational equation based on heat conduction equation and field equations are constructed and numerically solved to obtain the responses in terms of time histories, bending moment in fire and time to failure against axial load ratio. The heat flux is high enough to affect material properties of the structure and their variation with temperature is taking into account in the mathematical formulation. Results show that heat flux resulting from fire action transforms the buckling problem occurring at room temperature into a bending one. Non-reversible responses and sooner arising of failure are observed for Beam vibration Axial load ratio ISO 834 fire Parametric fire Structural failure Constructional ISO 834 fire even for axial load ratio not able to cause buckling at room temperature. Unlike the case of ISO steel fire, parametric fire improves reversible deflections within the exposure time and later occurring of failure.

\section{INTRODUCTION}

Structural behavior under temperature change has been of number of analytical, computational and experimental studies performed by several researchers (Aditya 2021; Al-Hamd 2020; Yaobing 2018; Kingsley 2018; Abbas 2016; Harshad 2016; Feng 2012; Nubissie 2011; Mourão 2007; Liu 2006; Ribeiro 2005; Buchanan 2001; Rotter 2000). Mechanical machines often operate under diverse temperature conditions (Nubissie 2011). In internal combustion engines, rocket systems, movement of satellites etc. the conditions are particularly temperature-sensitive. Thermal effects are frequently ignored in research and this may yield totally incorrect results. Literature shows that even moderate change in temperature leads to huge alteration of structural vibration properties (Yaobing 2018).

In civil and structural engineering but also in marine engineering, elevated temperatures are often caused by fire leading to material properties alteration. As a result the performance of these structures is affected due to unwanted dynamic responses and their integrity is sacrificed due to buckling. (Mourão 2007) analyzed the behavior of steel beams under uniform temperature

Manuscript received: 6 August 2021

Revised: 5 October 2021,

Accepted: 27 October 2021.

1jmetsebo@gmail.com (Corresponding Author) rising. The study covered beams under several load levels and presented the variation of deflection, critical temperature, bending moment, normal force and stresses with temperature. No type of fire is mentioned in this study and the method is straight computational with the aid of computer software ANSYS. (Seputro 2001) did similar study with computer software SAFIR but considered some types of fire.

(Ndoukouo 2011; Nubissie 2011; Avsec 2007) developed mathematical models where fundamental thermomechanical properties of state are functions of temperature. (Avsec 2007) validated the mathematical model by comparison with experimental data and obtained satisfactory agreement. (Yaobing 2018) used the extended Hamilton principle to model the vibration characteristics of EulerBernoulli beams under moderate thermal loads and mechanical excitations. (Feng 2012) applied the principle of minimum acceleration in dynamics of elastic plastic continua coupled with dynamic finite difference to numerically compute the responses of steel beams at elevated temperatures. In the same line with (Seputro 2001; Ndoukouo 2011; Feng 2012) considered a beam supporting transverse mechanical load and ISO 834 fire. 
The present study is devoted to the analysis of vibration characteristics as well as critical temperature at failure of a vertical metallic beam supporting simultaneous actions of axial load and fire, based on mathematical model and numerical simulation. Two types of fire are considered; ISO 834 fire which is the standard fire and parametric fire which is reported by the literature to be closer to the real fire situation. The structure and modeling are presented in Section II, while section III focuses on numerical simulation, results and discussion, with sub-section III.1 for ambient temperature, sub-section III. 2 concentrates on ISO 834 fire and sub-section III.3 focuses on parametric fire. A conclusion is drawn in section IV.

\section{STRUCTURE, MATHEMATICAL MODELING AND NUMERI- CAL SCHEME}

\section{The structure}

Consider a beam-column submitted to axial load and fire exposure. This situation is common in civil and structural Engineering (buildings and bridges) but also in marine Engineering (offshore). The system consists of an elastic beam with mass $m$, density $\rho$, young modulus $E$, length $l$, inertial moment $I$ and a rectangular cross section $A$. An axial load $P$ is applied to the beam which simultaneously undergoes the effect of an external fire. Two types of fire should be studied; the ISO 834 fire and the parametric fire. Under the influence of fire, the beam temperature changes with time and reaches high values that affects its material properties which are called to vary with temperature as the beam vibrates. The coordinates system associated with the beam (figure 1) of width $b$ and thickness $h$ consists of a Cartesian frame with origin $O$, coinciding with the bottom edge midpoint of the beam. The $x$-axis is oriented toward the beam length such that $0 \leq x \leq l$ the $y$-axis is parallel to the beam width such that $-\frac{b}{2} \leq y \leq \frac{b}{2}$ and the z-axis parallel to the thickness with $-\frac{h}{2} \leq z \leq \frac{h}{2}$.

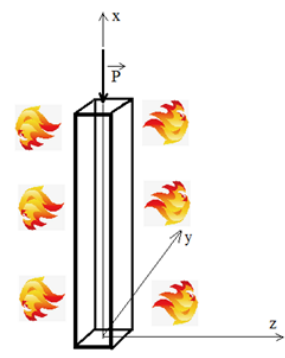

Figure 1 Sketch of the investigated system

\section{Mathematical modeling}

The following assumptions are made :

- The fire is uniformly distributed along the beam;

- Material degradation is not considered though material properties are temperature-dependent;

- The study is made under the limit of validation of Hooke law.

The system modeling the beam behavior in such a situation consists of the heat conduction equation coupled with the field equation written respectively as follows (Timoshenko 1951; Nayfeh 1979; Kant 1991; Huang 2002)

$$
c_{p}(T) \frac{\partial T}{\partial t}=\lambda_{T}\left(\frac{\partial^{2} T}{\partial x^{2}}+\frac{\partial^{2} T}{\partial z^{2}}\right)-\alpha_{T} E(T) \frac{\partial \varepsilon}{\partial t}
$$

$$
\begin{array}{r}
\frac{m}{l} \frac{\partial^{2} U}{\partial t^{2}}+c \frac{\partial U}{\partial t}+E(T) I \frac{\partial^{4} U}{\partial x^{4}}+\left[E(T) A \alpha_{T} \Delta T+P\right] \frac{\partial^{2} U}{\partial x^{2}} \\
=\frac{\partial^{2} M_{T}}{\partial x^{2}}+\frac{E(T) A}{2 l}\left(\int_{0}^{l}\left(\frac{\partial U}{\partial x}\right)^{2} d x\right) \frac{\partial^{2} U}{\partial x^{2}}
\end{array}
$$

Equation (1) must be completed with prescribed boundary and initial conditions on temperature. Into equation (2), the term $E(T) A \alpha_{T} \Delta T$ refers to the internal axial load developed in the member as a result of thermal expansion against ends restraints. Equation (2) has to be completed with given initial and boundary conditions on displacement. A beam with clamped-clamped ends has been considered in this study In equations (1) and (2) , $U$ is the transversal displacement of the beam, $\alpha_{T}$ is the thermal conductivity, $T(x, t)$ is the temperature field, $\varepsilon(x, t)$ the total strain, $c_{P}(T)$ the specific heat, $\lambda_{T}$ the coefficient of thermal expansion, $\Delta T=T-T_{0}$ the temperature difference, $T_{0}$ the room temperature and $M_{T}$ the thermal moment given by the following expression :

$$
M_{T}=E(T) b \alpha_{T} \int_{-h / 2}^{h / 2}\left(T(x, z, t)-T_{0}\right) z d z
$$

In Eqs. (1)-(2), since the temperature varies in a range that affects material properties, one has to take into account the variation with temperature of material properties (see appendix). One is concerned for the purpose of this study with constructional steel. According to the above assumption, the mass $m(T)$ of the beam is taken to be constant. It is also assumed that the heat flow that acts on the beam is much slower than the mechanical stress-strain variations. Therefore, the temperature distribution can be considered independent of the deformation and can thus be defined by a given function which represents the quasi-steady state of the heat transfer equation (1). This allows the reduction of the conductivity equation. The temperature field is assumed to be uniform along the beam and the thermal moment intervening in equation (2) thus vanishes. The design fire is modeled by an international standard time-temperature law defined for ISO 834 from (Eurocode 3 2003) by:

$$
T(t)=T_{0}+345 \ln (8 t+1)
$$

The parametric fire will be modeled later. Thereafter, the system of equations (1)-(2) is reduced to the following dimensionless equation.

$$
\begin{array}{r}
\frac{\partial^{2} U}{\partial t^{2}}+\mu g(t) \frac{\partial U}{\partial t}+g(t) k_{e}(t) \frac{\partial^{4} U}{\partial x^{4}}+g(t)\left[\alpha+\gamma \alpha_{T} \Delta T k_{e}(t)\right] \frac{\partial^{2} U}{\partial x^{2}} \\
=\epsilon \beta g(t)\left(\int_{0}^{1}\left(\frac{\partial U}{\partial x}\right)^{2} d x\right) \frac{\partial^{2} U}{\partial x^{2}}
\end{array}
$$

Where, function $g(t)$ and $k_{e}(t)$ are given in Eq. (17)-(19) (see appendix) .

$$
\alpha=\frac{P L^{2}}{E_{0} I} ; \quad \beta=\frac{A L^{2}}{I}
$$

$\alpha$ is the axial load ratio and $\epsilon$ the nonlinearity coefficient. The critical Euler load is classically given by :

$$
P_{c r}=\pi^{2} \frac{E I}{L^{2}}
$$


Therefore, setting $\alpha_{c r}=\frac{P_{c r} L^{2}}{E I}$, one obtains $\alpha_{c r}=\pi^{2}$.

It should be pointed out that $P_{c r}$ is influenced by temperature change and can be written at any temperature as follows :

$$
P_{c r}(T)=P_{20} k_{e}(T)
$$

Where $k_{e}(T)$ is given in Eq. (A.2). The variation of $P_{c r}$ with temperature is plotted in fig. 2. It is a decreasing function of temperature.

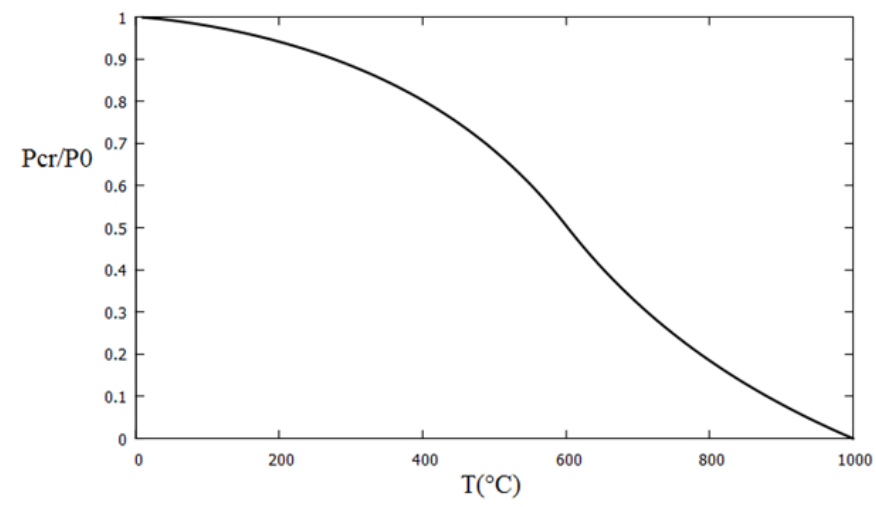

Figure 2 Variation with temperature of critical load ratio

\section{NUMERICAL SIMULATION, RESULTS AND DISCUSSIONS}

Nonlinear integral partial differential equation (5) is numerically computed for constructional steel with the following parameters values.

$$
\begin{gathered}
E=2.1 \times 10^{11} \mathrm{~Pa} ; \quad I=5.2 \times 10^{-7} \mathrm{~m}^{2} ; \quad \rho=7800 \mathrm{~kg} \cdot \mathrm{m}^{-3} ; \\
A=2.5 \times 10^{-3} \mathrm{~m}^{2} ; \quad L=0.5 \mathrm{~m} ; \quad \alpha_{T}=14 \times 10^{-6^{\circ} \mathrm{C}^{-1}}
\end{gathered}
$$

Initial and boundary conditions associated with equation (5) are set as follows. For the concern of boundary conditions, a beam clamped at both ends is considered as this is one of the frequently found situations for structural components in engineering.

$$
\begin{gathered}
U(0, t)=\frac{\partial U(0, t)}{\partial x}=0 ; \quad U(1, t)=\frac{\partial U(1, t)}{\partial x}=0 \\
U(x, 0)=\frac{\partial U(x, 0)}{\partial t}=0
\end{gathered}
$$

Zero initial conditions on deflection and velocity have been considered and associated with a small transverse load $q=5 \mathrm{~N} / \mathrm{m}$ for the sake of nontrivial solutions.

A full discretization using centered finite differences within space of PDE (5) associated with Runge Kutta 4 on time, has been used for the purpose of numerical method. The axial load ratio $\alpha$ is varied as the temperature increases in the beam and the previous equation is numerically solved in the sake of vibrational behavior of the structure.

\section{Behaviour at ambient conditions}

Fig. 3 presents the deflection versus position within the midline of the beam at ambient conditions. It can be observed that the mid-span position admits maximum deflection amplitude. The effect of temperature on this result will be presented in the next sections.

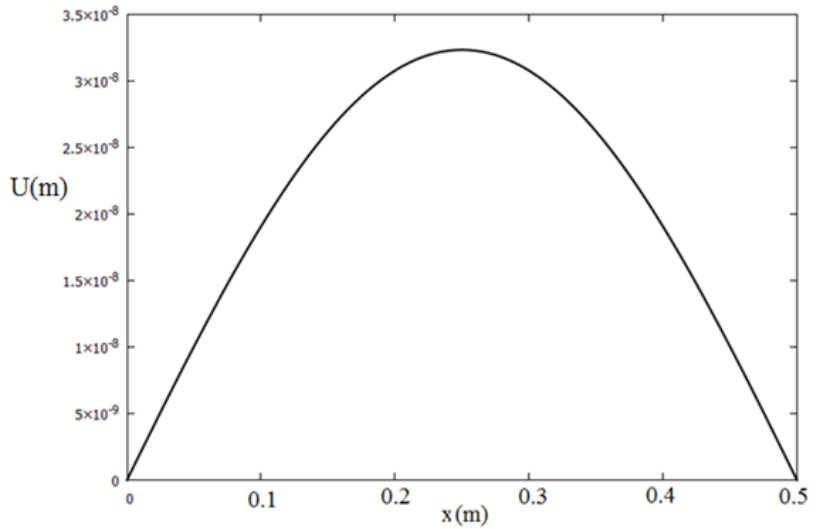

Figure 3 Deflection versus position on the beam mid-line at ambient temperature for $\alpha=0.5$

Figures 4(a)-4(c) present the time histories of the beam midspan at ambient temperature for different values of axial load ratio, namely $\alpha=0.25$ (fig.4(a)), $\alpha=0.5$ (fig. 4(b)) and $\alpha=0.75$ (fig.4(c)). It can be seen that the deflection has constant amplitude within the time and there is no notably change in amplitude nor in frequency for these different values of axial load ratios. The effect of fire on these responses are investigated in the next sections. Figures 4(d) and 5(a) present the time history and bending moment at beam mid-span for higher value of axial load ratio, $\alpha=9.0$. It is found that amplitude and frequency of oscillations had increased compared to the previous cases corresponding to smaller values of $\alpha$ (figs. 4(a)-4(c)). Meanwhile, the oscillations remain regular within the time. However as from the critical value of axial load $(\alpha=10.0)$, oscillations lose their regular behaviour and the beam responds with increasing amplitude within the time. This can be seen in figures 5(b) and 5(c) presenting mid-span time history and bending moment at room temperature for critical value of axial load ratio, $\alpha=10 \approx \alpha_{c r}$. It can be seen in these figures that the responses explode due to the buckling of the structure at critical axial load ratio.

This inspires to plot the time to failure of the beam as a function of axial load ratio at room temperature (see fig. 5(d)). To obtain this figure, a failure criterion is defined (see eq.(11)) comparing the resistant moment of the beam and the bending moment resulting from the applied loads.

$$
M(t) \geq \eta M_{c r}
$$

where

$$
M_{c r}=\sigma_{0} \times A
$$

$\sigma_{0}$ is the temperature free yield stress and $\eta$ is a safety factor.

It is observed that the time to failure is a decreasing function of the axial load ratio. The beam undergoes rapid collapse for $\alpha$ greater than the critical value $\alpha_{c r} \approx 10.0$, and the higher the value of $\alpha$, the sooner the failure. Eqs. (11)-(12) show that the time to failure grows with the cross section of the beam. 


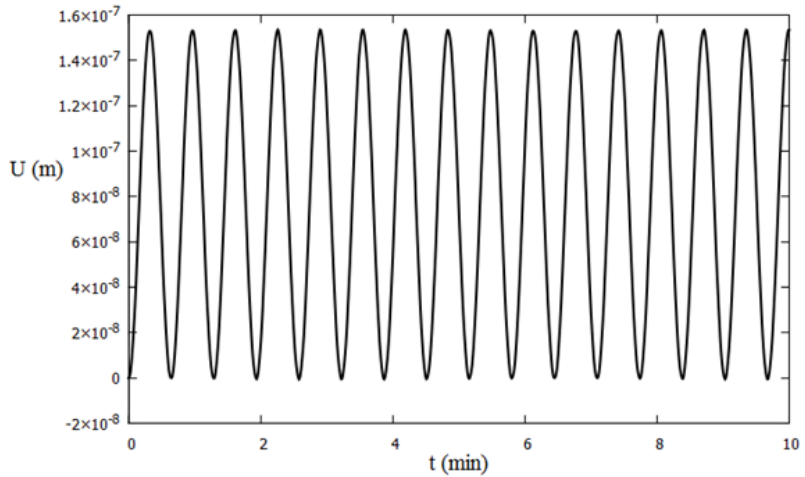

(a) Time history at room temperature for $\alpha=0.25$

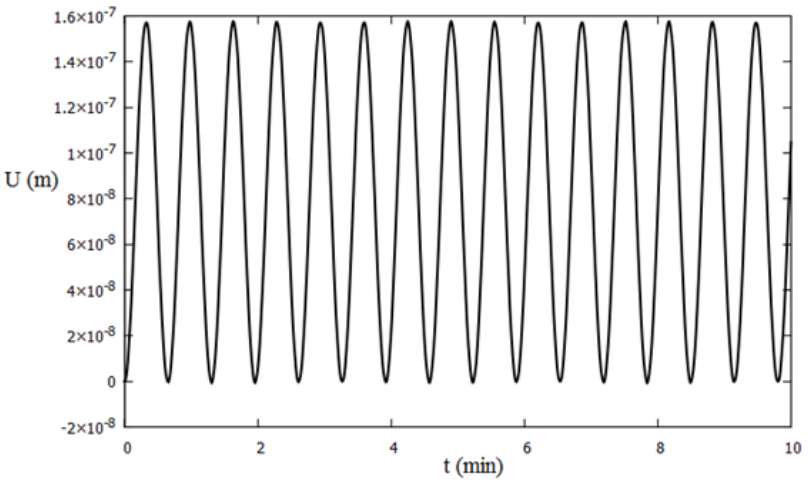

(b) Time history at room temperature for $\alpha=0.5$

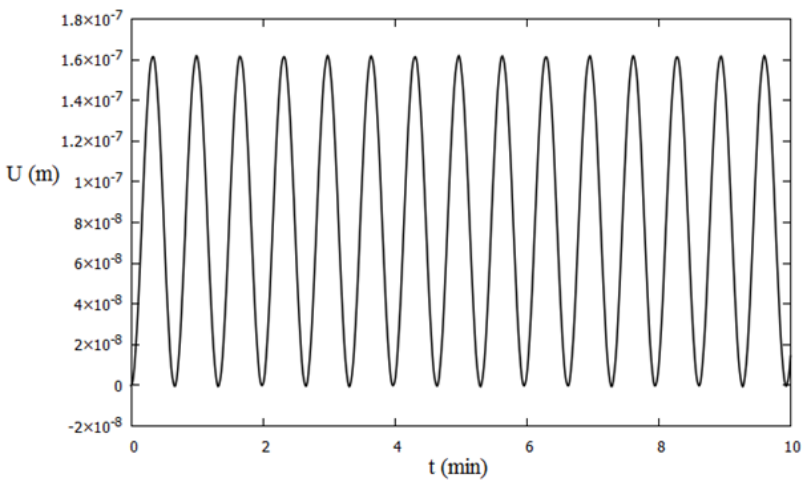

(c) Time history at room temperature for $\alpha=0.75$

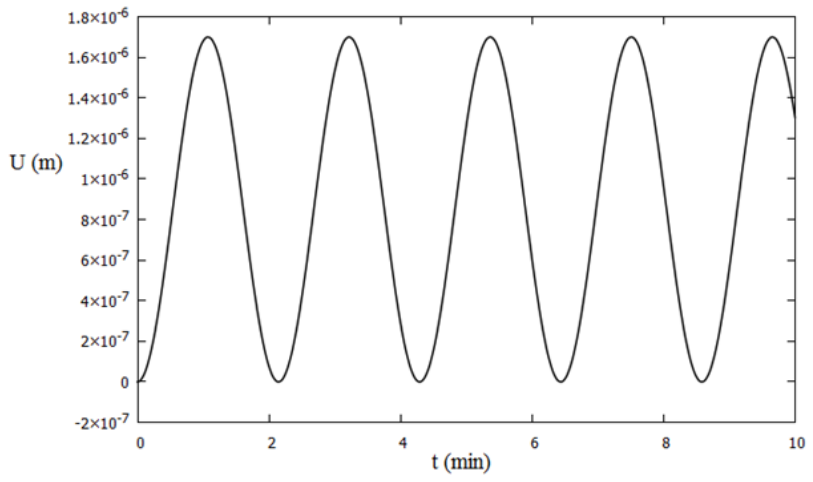

(d) Time history at room temperature for $\alpha=9.0$

Figure 4 Time history at room temperature for different values of $\alpha$

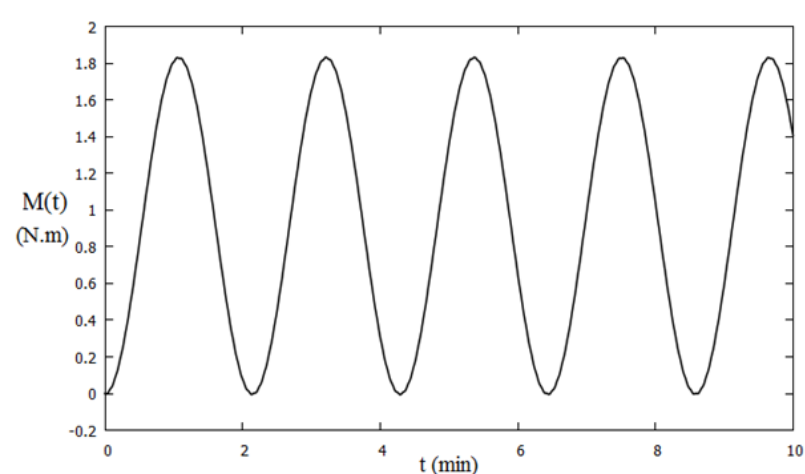

(a) Bending moment at room temperature for $\alpha=9.0$

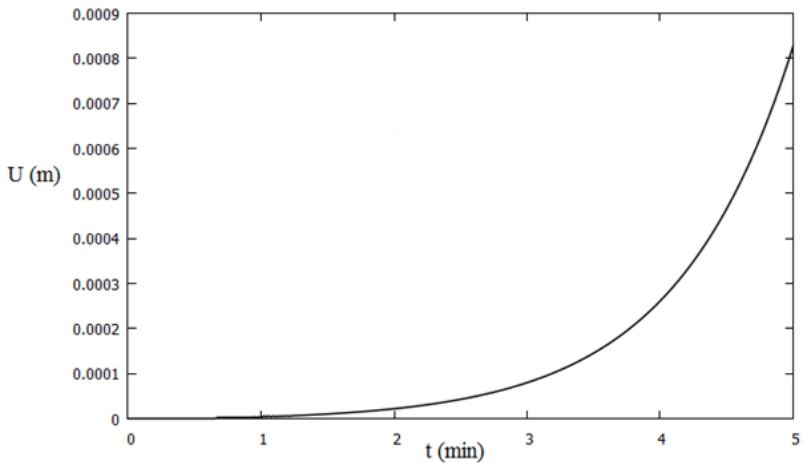

(b) Time history at room temperature for $\alpha=10.0$

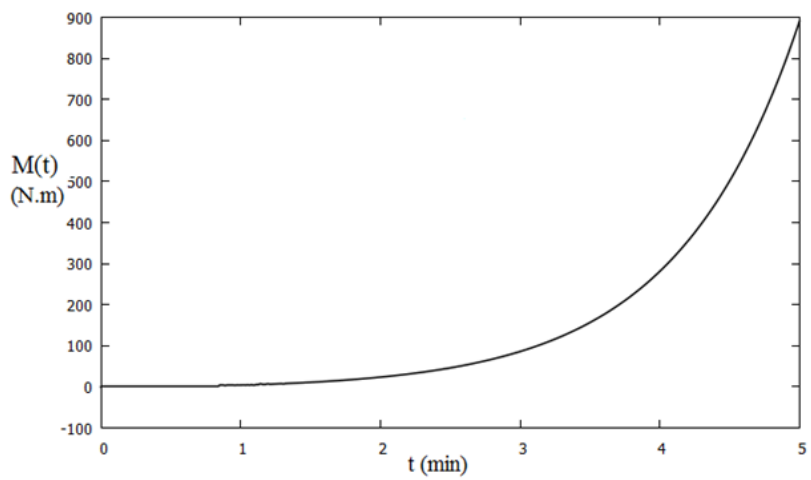

(c) Bending moment at room temperature for $\alpha=10.0$

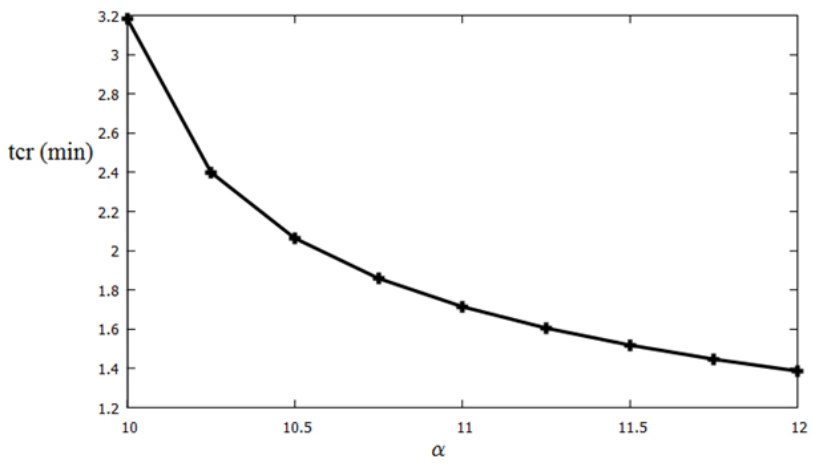

(d) Time to failure against axial load ratio at ambient temperature

Figure 5 Time history and Bending moment at room temperature for different values of $\alpha$ 
Observing fig. 5(d), an approximated analytical expression given $t c$ as a function of axial load ratio $\alpha$ can be suggested as follows.

$$
t c=\frac{2.0}{\alpha-9.5}
$$

Such an expression is useful in practice as it allows designers to set some predictions from simple calculation. Eq. (13) gives a graph quite similar to that of fig. $5(\mathrm{~d})$ for $\alpha$ belonging to the interval $[10-12]$.

\section{Behaviour in presence of ISO fire 834}

Vibrational responses: In presence of an ISO 834 fire modeled by the time-temperature law (Eq.4), the following results are obtained. Figures 6 present mid-span time histories in presence of ISO 834 fire and mechanical load with axial load ratios $\alpha=0.25$ (Fig. 6(a)), $\alpha=0.5$ (Fig. 6(b)) and $\alpha=0.75$ (Fig. 6(c)) respectively. Figures 7 present the bending moment in fire for same conditions and parameters. It can be observed in opposition to the situation at ambient temperature previously presented in figures 4(a)-4(c) where amplitudes of oscillations were small and constant that in presence of fire, oscillations amplitudes keep increasing during the fire action. Moreover, a shift within the time towards positive values of the centers of oscillations is observed. This agrees with results obtained from computational software ANSYS and SAFIR (Seputro 2001; Mourão 2007).

It is also important to note that after some duration of fire exposure, oscillations lose their reversible character and amplitudes keep increasing with a faster speed. Figures 5-7 show that oscillation amplitudes increase with axial load ratio in presence of fire faster than in ambient conditions. In presence of fire, oscillations lose their reversible character sooner for greater values of $\alpha$. As an example, this happens after 50 minutes exposure to fire for $\alpha=0.25,40$ minutes for $\alpha=0.5$ and 35 minutes for $\alpha=0.75$, see Figures 7.

Figure 8 presents the mid-span time history in presence of fire for different positions along the beam. It is seen that the maximum deflection amplitudes are observed for the beam mid-span as was the case in figure 3 for ambient conditions. Figure 9 presents the beam deformation versus position on the beam mid-line in presence of fire for axial load ratio $\alpha=0.5$, at different temperature $T=100^{\circ} \mathrm{C}$ (Fig. 9b) and $\mathrm{T}=300^{\circ} \mathrm{C}$ (Fig. 9c). These responses are compared with those obtained at ambient conditions (Fig. 9a) in order to exhibit the influence of warming on the responses. It is observed that the deflection amplitude grows with temperature and is at $100^{\circ} \mathrm{C}$ three times the one at ambient conditions while at $300^{\circ} \mathrm{C}$ it worth about nine times the amplitude at room temperature.

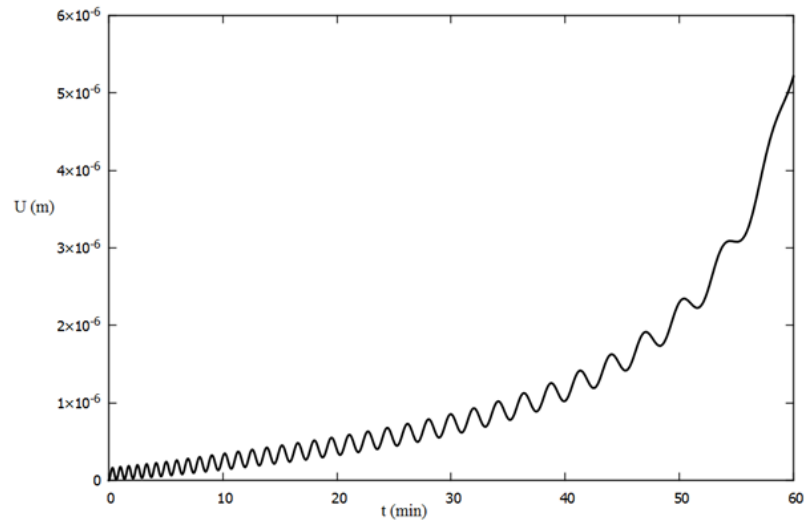

(a) Time history in presence of fire for $\alpha=0.25$

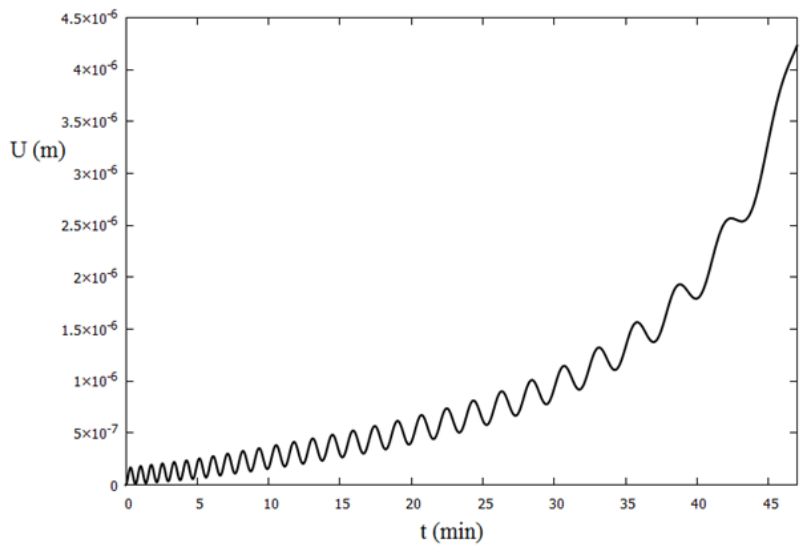

(b) Time history in presence of fire for $\alpha=0.5$

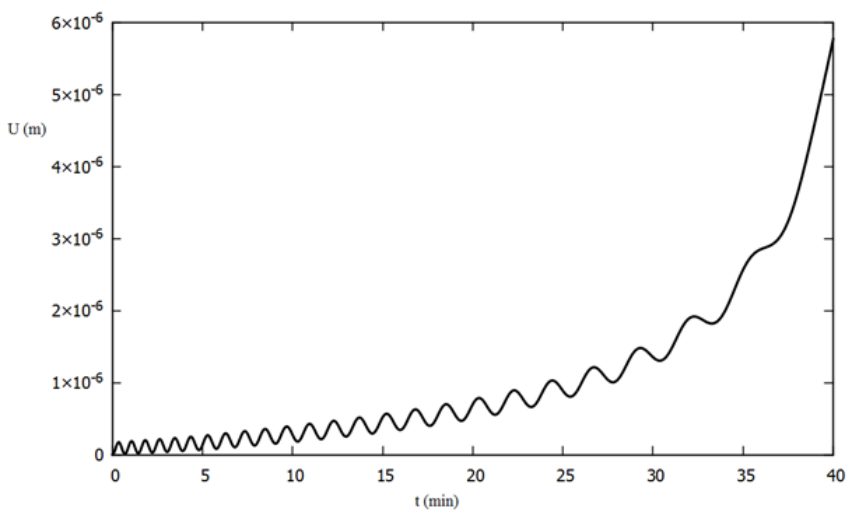

(c) Time history in presence of fire for $\alpha=0.75$

Figure 6 Time history in presence of fire for different values of $\alpha$ 


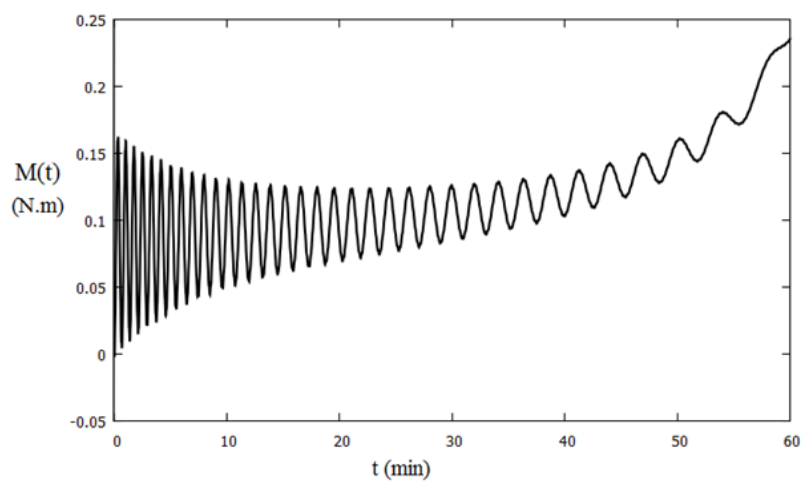

(a) Bending moment in fire for $\alpha=0.25$

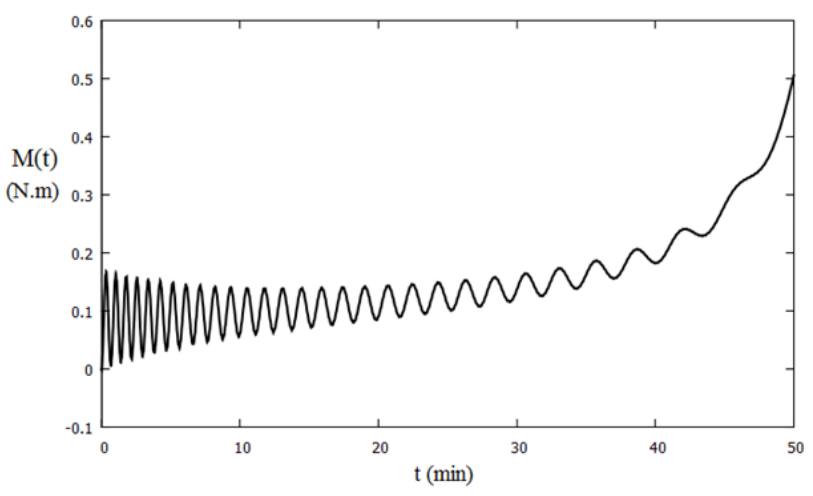

(b) Bending moment in fire for $\alpha=0.5$

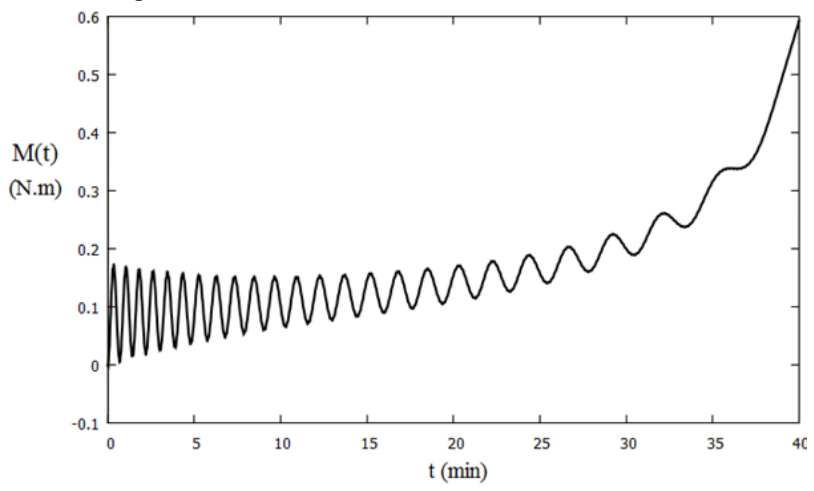

(c) Bending moment in fire for $\alpha=0.75$

Figure 7 Bending moment in fire for different values of $\alpha$

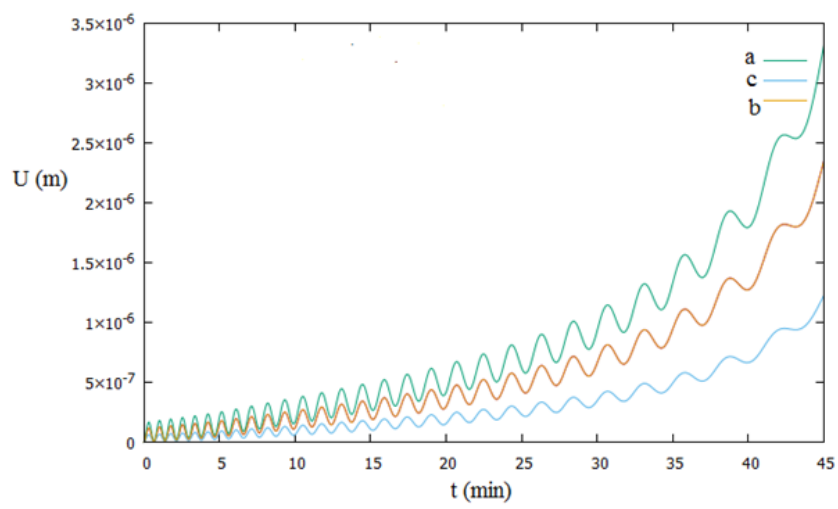

Figure 8 Time histories at different positions along the beam (a) mid-span, (b) height, (c) quarter.

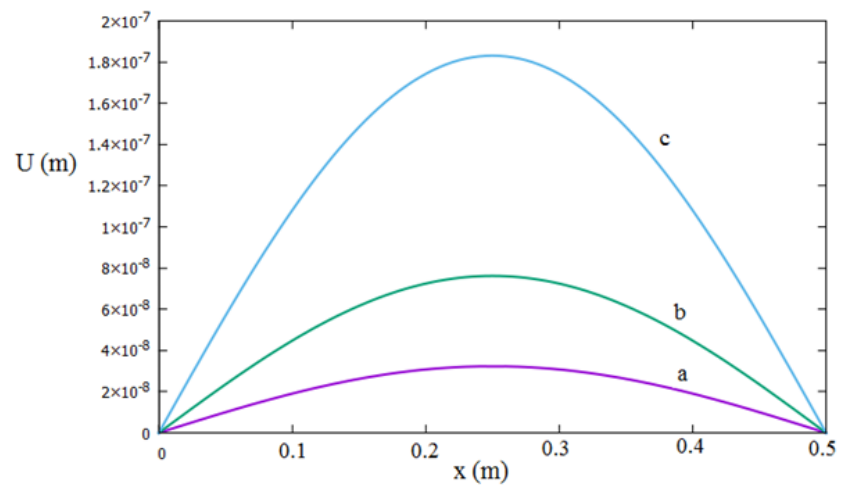

Figure 9 Deflection versus mid-line position of the beam at different temperatures. $\alpha=0.5$ (a) $T=20^{\circ} \mathrm{C}$, (b) $\mathrm{T}=100^{\circ} \mathrm{C}$, (c) $T=300^{\circ} \mathrm{C}($ at $\mathrm{t}=30 \mathrm{~min})$

Structural failure under ISO $\mathbf{8 3 4}$ fire: The above observation inspires to think of structural failure after some time spent by the structure under simultaneous actions of fire exposure and mechanical applied and internal axial loads. What is referred to as structural failure here is not necessarily the collapse of the structure but the fact of reaching a limit state of usage defined by the needed design. As one is dealing with civil and structural engineering components such as buildings or bridges, it is advantageous to define this limit so as to avoid structural damage which could be a risk for people or goods using the structure but also for firefighting personal. This is the reason why the elastic limit is considered as the limit state of usage in this study and as such a safety factor $\eta(0 \leq \eta \leq 1)$ is introduced into the failure criterion under fire. Hence conditions set in eqs (11)-(12) are used with actually the resistance moment in fire being a function of time as it is influenced by temperature (Seputro 2001; Ndoukouo 2011; Nubissie 2011). The bending moment in fire results of all mechanical and thermal action on the structure. Eq.(12) becomes :

$$
M_{c r}(t)=\sigma_{c r}(t) \times A=\sigma_{0} k_{y}(t) A
$$

$k_{y}(t)$ is the reduction factor of the yield strength defined as a sequential relation of temperature and thus of time (see eqs. A-7A-8 (A.7)-(A.8)), $\sigma_{0}$ is the temperature free yield stress. Condition (11) associated with eq.(14) enables to obtain Fig. 10 presenting the time to failure of the structure in fire as a function of axial load ratio. It is observed that the time to failure decreases as the axial load ratio increases. This time indicates the maximum duration the fire fighting personal disposes in order to proceed with the rescue of people and goods present in the structure without enormous risk of damaging the mechanical integrity of the carrying structure. Figure 11 presents the critical deflection reached with corresponding time to failure of the fire-exposed structure. These deflections are increasing function of the critical time. 


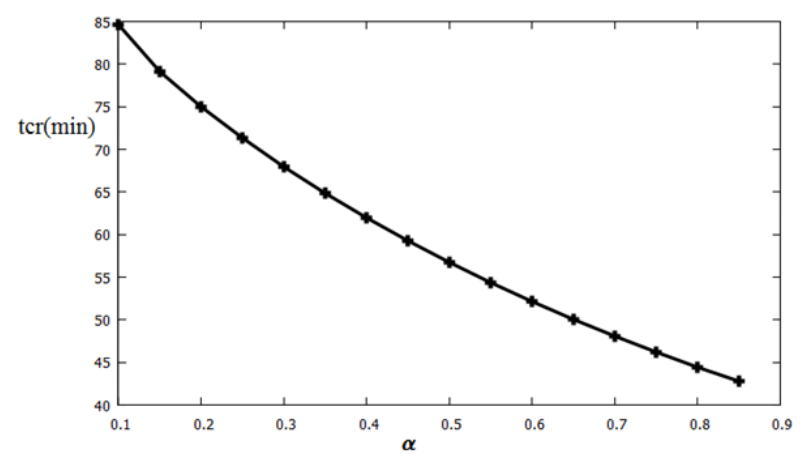

Figure 10 Failure time as a function of axial load ratio under ISO 834 fire

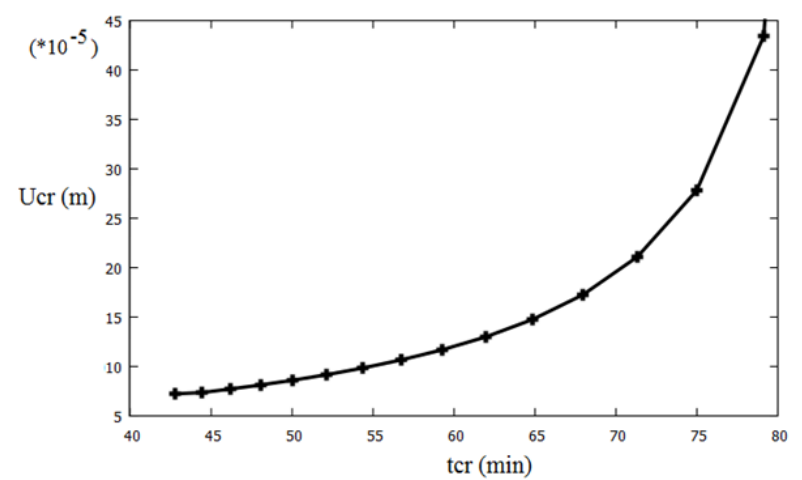

Figure 11 Critical deflection in fire versus time to failure for ISO 834 fire

\section{Behaviour in presence of parametric fire}

Vibrational responses: For the sake of comparison of results obtained from ISO 834 fire, we consider a more realistic model in this section, namely, the parametric fire. It is made of a burning phase where fire grows following the standard ISO curve and a cooling phase following a linear heating rate. For the considered parametric fire, the growing period lasts for the first twenty minutes and the cooling phase follows a decay rate of $625^{\circ} \mathrm{C}$ per hour according to Eurocode reference decay rate (ECI, 1994). The corresponding time-temperature law can be written as follows :

$$
T(t)=\left\{\begin{array}{l}
T_{0}+345 \ln (8 t+1) \quad: t \leq 20 \min \\
-10.416(t-20)+781 \quad: t \geq 20 \mathrm{~min}
\end{array}\right.
$$

Applying this type of fire to the investigated system, the following results are obtained.

Figures 12 and 13 present the mid-span time history and bending moment in fire for parametric fire with mechanical axial load ratio equal to 0.5 . Figure 14 presents the mid-span time history in fire for axial load ratios $\alpha=1.0$. Figures 15 and 16 present the mid-span time history and bending moment in fire for $\alpha=2.0$. Unlike the previously studied case of ISO 834 fire, it is observed that the deflection does not increase abruptly with fire exposure time.

There is an increase of deflection during the burning phase followed by a decrease during the cooling phase. This agrees with results obtained with the aid of computational software SAFIR (Seputro 2001). Moreover, due to the cooling, the rapid increase of deflection with sooner arise of irreversible deformation as was the case with ISO 834 fire is not observed for parametric fire. It is possible for structure under this type of fire to undergo elastic deformation for axial load ratios greater than the values that induce irreversible responses under ISO 834 fire. This will obviously impacts structural failure under parametric fire differently from what obtained with ISO 834.This can be understood since parametric fire burns up to a given duration (20 minutes for the considered case) and starts decaying afterwards whereas this is not the case for ISO fire.

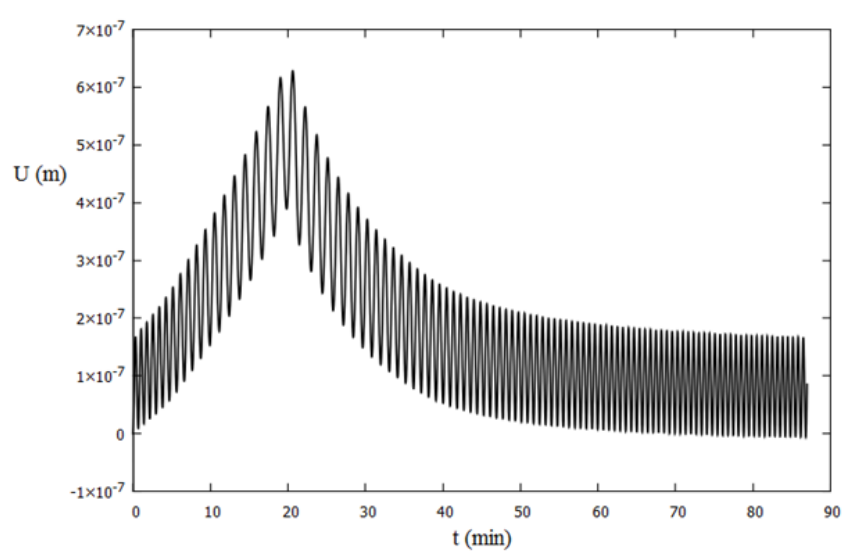

Figure 12 Time history at beam mid-span for parametric fire $\alpha=0.5$

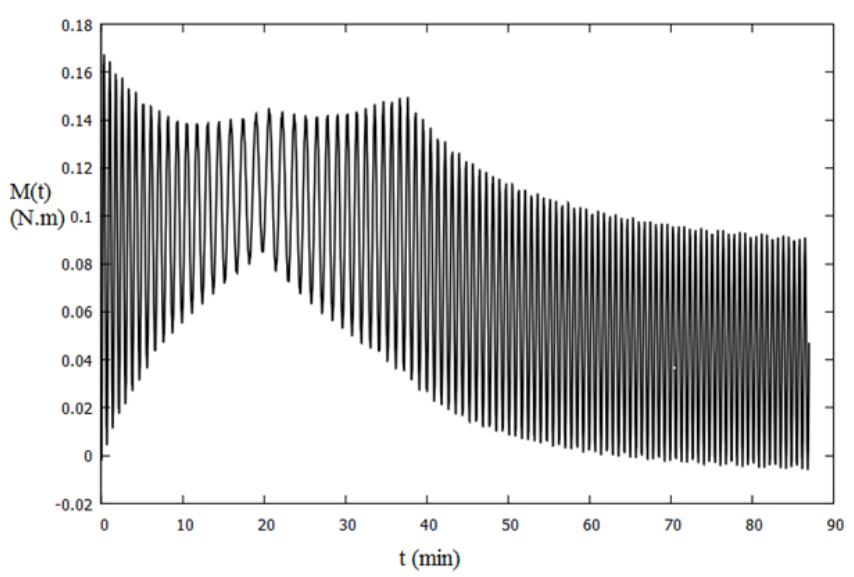

Figure 13 Bending moment in fire at beam mid-span for parametric fire. $\alpha=0.5$ 


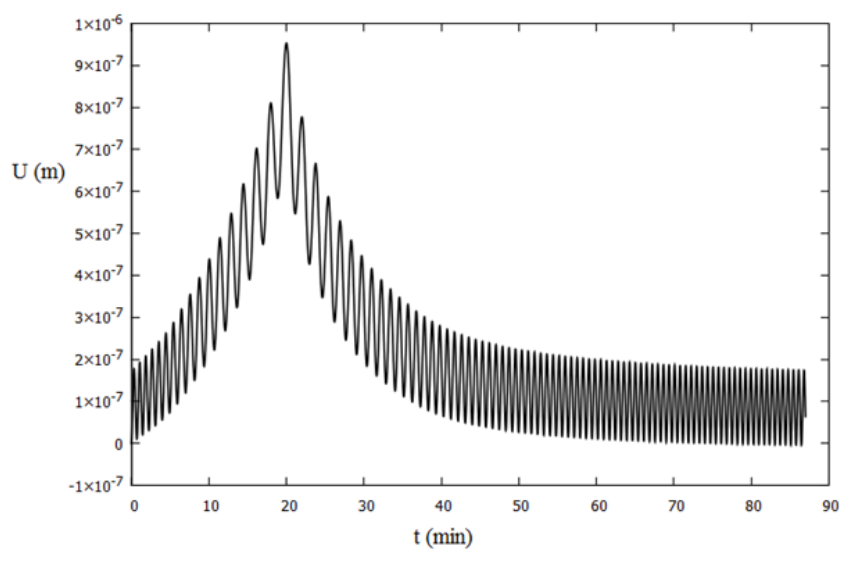

Figure 14 Time history at beam mid-span for parametric fire. $\alpha=1.0$

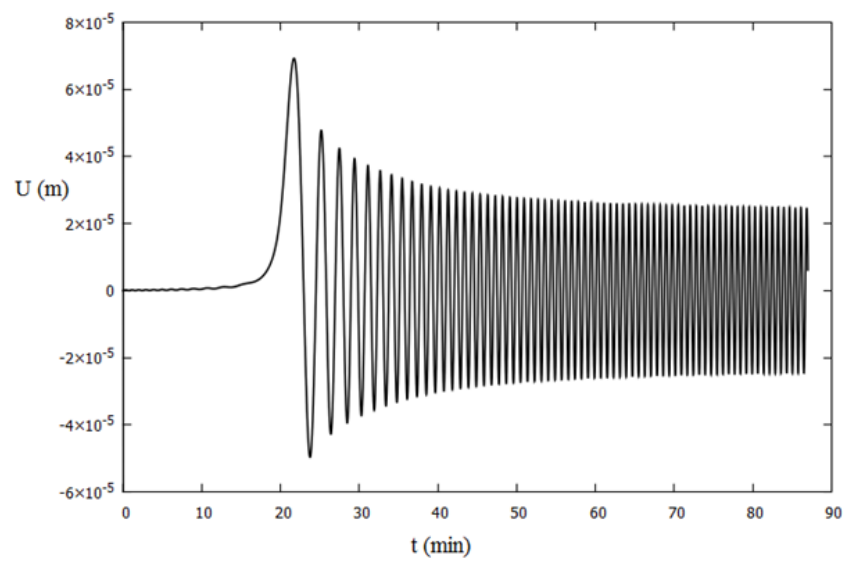

Figure 15 Time history at beam mid-span for parametric fire. $\alpha=2.0$

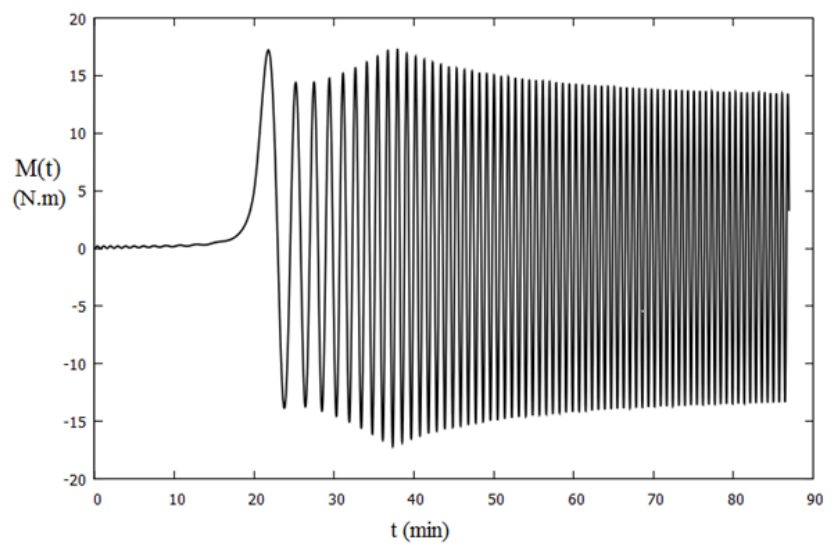

Figure 16 Bending moment in fire at beam mid-span for parametric fire. $\alpha=2.0$
Structural failure under parametric fire: Vibrational analysis made in previous section for parametric fire exposed beam has given results with some important differences as regard to those obtained under Iso fire. This section investigates the structural failure of the beam under simultaneous action of mechanical axial load and parametric fire. Taking into account the time-temperature law modeling the parametric fire (eq.13) and the failure conditions (eq.11) and (eq.12) the following results are obtained. Figure 17 presents the time to failure of the beam as a function of axial load ratio while figure 18 presents the variation of the reached maximum deflection with the corresponding time to failure. It is seen that the time to failure is a decreasing function of the axial load ratio. It can be noted that there is no failure by vibration for axial load ratio less than $\alpha=2.0$ whereas one had obtained failure by vibration with axial load ratio less than $\alpha=1.0$ in presence of ISO fire (see fig. 10). This can be explained by energy and momentum redistribution associated with internal axial load in the beam due to cooling phase of the parametric fire.

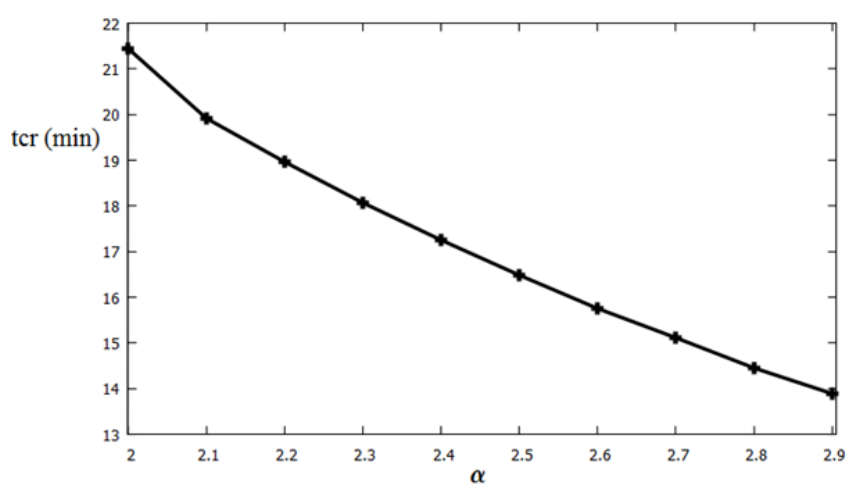

Figure 17 Failure time as a function of axial load ratio under parametric fire

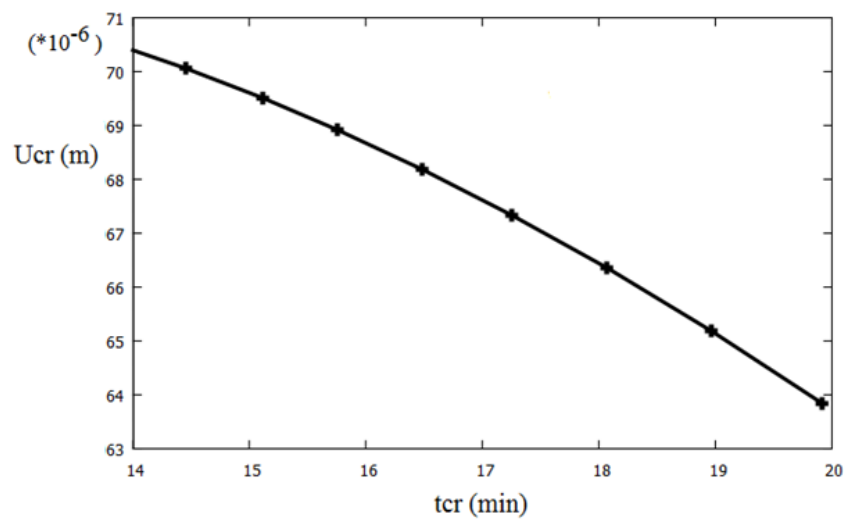

Figure 18 Critical deflection in fire versus time to failure for parametric fire 


\section{CONCLUSION}

Vibrational behavior as well as structural failure of a metallic clamped column, supporting mechanical axial load and simultaneous action of fire exposure have been investigated. Two types of fire have been considered, namely standard ISO fire 834 and parametric fire. A model based on the heat conduction equation and field equations with inclusion of temperature-dependence of physical parameters of the structure as well as internal axial load due to thermal expansion has been considered. For the purpose of numerical simulation of the obtained PDEs, real numerical data from constructional steel have been chosen. Results have been presented in terms of vibrational analysis and structural failure in fire. For vibrational analysis concern, beam deformation against position for several temperatures, time histories as well as bending moment in fire have been presented for the two types of fire. As per the structural failure concern, structural failure conditions have been set and results presented in terms of time to failure as a function of axial load ratio and maximum deflection reached against critical time for ISO 834 fire and for parametric fire.

As far as the vibrational analysis is concerned it has been obtained that for ISO fire the deflection amplitude grows with time and the axial load ratio. Higher values of axial load ratio generate higher deflection amplitude with rapid increase within the time and sooner arrival of irreversible responses. The axial load ratio could not exceed some critical value for this type of fire without sooner apparition of irreversible responses. Meanwhile in presence of parametric fire, deflection amplitudes increase during the burning period and decrease during the cooling phase. However this type of fire shows an improvement of reversible deflection within the time. Moreover the responses do not diverge for axial load ratio greater than those giving irreversible responses under ISO fire, although the deflection and bending moment present higher values for greater values of axial load ratio.

As per the structural failure concern, the time to failure has been obtained as a decreasing function of the axial load ratio for each type of fire. Under ISO 834 fire the time to failure has been obtained for axial load ratio values less than 1.0, with sooner irreversible responses for greater values of axial load ratios. Meanwhile under parametric fire there was no failure by vibration for axial load ratio less than $\alpha=2$ unlike the case of ISO fire 834 .

\section{APPENDIX}

Variation laws with temperature of some material properties of the structure (Seputro 2001; Eurocode 2003; Ndoukouo 2011; Feng 2012). The modulus of elasticity can be written at any temperature as:

$$
E=E(T)=E_{0} k_{e}(T)
$$

In Eq. A-1, $k_{e}(T)$ denotes the reduction factor of the Young modulus and can be obtained as a function of temperature for the given material the structure is made with. $E_{0}$ represents the value of the Young modulus at ambient temperature $T_{0}$. In the case of constructional steel for example $k_{e}(T)$ can be given as follows :

$$
k_{e}(T)=\left\{\begin{array}{l}
1.0+\frac{T}{2000 \ln \frac{1}{1100}}: \quad 20^{\circ} \mathrm{C} \leq \mathrm{T} \leq 600^{\circ} \mathrm{C} \\
690 \times \frac{1-\frac{T}{1000}}{T-53.5}: \quad 600^{\circ} \mathrm{C} \leq \mathrm{T} \leq 1000^{\circ} \mathrm{C}
\end{array}\right.
$$

For the concern of variation with temperature of the effective length of the beam, the thermal elongation can be written as a function of thermal expansion :

$$
l(T)=L\left(1+\varepsilon_{t h}\right)=L\left(1+\alpha_{T} \Delta T\right)=L g(T)
$$

$l(T)$ represents the effective length of the beam at current temperature and $L$ the length at room temperature. Function $g(T)$ is given by :

$$
g(T)=\left\{\begin{array}{l}
1+1.2 \times 10^{-5} \mathrm{~T}+0.4 \times 10^{-8} \mathrm{~T}^{2}-2.416: \\
20^{\circ} \mathrm{C} \leq \mathrm{T} \leq 750^{\circ} \mathrm{C} \\
1+1.1 \times 10^{-2} \mathrm{~T}: \quad 750^{\circ} \mathrm{C} \leq \mathrm{T} \leq 860^{\circ} \mathrm{C} \\
2 \times 10^{-5} \mathrm{~T}-6.2 \times 10^{-3} \quad: 860^{\circ} \mathrm{C} \leq \mathrm{T} \leq 1200^{\circ} \mathrm{C}
\end{array}\right.
$$

The variation with temperature of the specific heat is given as follows :

$$
c_{p}(T)=\left\{\begin{array}{l}
425+7.73 T-1.69 \times 10^{-3} T^{2}+2.22 \times 10^{-6} T^{3}: \\
20^{\circ} \mathrm{C} \leq T \leq 600^{\circ} \mathrm{C} \\
666+\frac{13002}{738-T}: \quad 600^{\circ} \mathrm{C} \leq T \leq 735 \circ \mathrm{C} \\
545+\frac{17820}{T-731}: \quad 735 \circ \mathrm{C} \leq T \leq 900 \circ \mathrm{C} \\
650: 900 \circ \mathrm{C} \leq T \leq 1200 \circ \mathrm{C}
\end{array}\right.
$$

Meanwhile the temperature-dependent thermal conductivity is given as :

$$
\lambda_{T}=\left\{\begin{array}{l}
54-3.33 \times 10^{-2} \mathrm{~T}: \quad 20^{\circ} \mathrm{C} \leq \mathrm{T} \leq 800^{\circ} \mathrm{C} \\
27.3: \quad 800^{\circ} \mathrm{C} \leq \mathrm{T} \leq 1200^{\circ} \mathrm{C}
\end{array}\right.
$$

The yield strength of the material at given temperature $\sigma(T)$, is related to the value of room temperature by the following relation

$$
\sigma(T)=\sigma_{0} k_{y}(T)
$$

The reduction factor $k_{y}(T)$ varies with temperature as follows :

$$
k_{y}(T)=\left\{\begin{array}{l}
1.0: \quad 20^{\circ} \mathrm{C} \leq \mathrm{T} \leq 215^{\circ} \mathrm{C} \\
(905-T) / 690: \quad 215^{\circ} \mathrm{C} \leq T \leq 905^{\circ} \mathrm{C}
\end{array}\right.
$$




\section{Conflicts of interest}

The authors declare that there is no conflict of interest regarding the publication of this paper.

\section{Availability of data and material}

Not applicable.

\section{LITERATURE CITED}

Abbas, Y. A. S. A. R. M. I., H. Al-Salloum, 2016 Post-heating response of concrete-filled circular steel columns. KSCE Journal of Civil Engineering 21: 1367-1378.

Aditya, A.-K., K., 2021 Post-fire exposure behaviour of circular concrete-filled steel tube column under axial loading. Int. Journal of Steel Structures 21: 52-56.

Al-Hamd, G. M. M. S. C. L., R., 2020 Influence of loading ratio on flat slab connections at elevated temperature : A numerical study. Frontiers of Structural and Civil Engineering 14: 664-674.

Avsec, O. M., J., 2007 Thermal vibrational analysis for simply supported beam and clamped beam. Journal of Sound and Vibration 308: 514-525.

Buchanan, . A., 2001 Structural Design for Fire Safety. Wiley.

Eurocode, 2003 Design of Steel Structures-Structural Fire Design. European Committee for Standardization.

Feng, Y. L., X., 2012 Criteria of limiting temperature and parametric analysis of the large deflection behavior for fully restrained steel beam. Sci. China Technology 55: 264-275.

Harshad, K. S., D., 2016 Behavior of steel structure under the effect of fire loading. Journal of Engineering Research and Applications 6: 42-46.

Huang, K. G., H., 2002 Buckling and initial postbuckling behavior of sandwich beams including transverse shear. AIAA journal 57: 2331-2335.

Kant, P. H., T., 1991 Buckling load of sandwich columns with a higher order theory. Journal of Reinforced Composites 10: 102109.

Kingsley, C. G. J. B. S. J. U. S. . A. A., U., 2018 Design of continous concrete filled steel tabular column in fire. Thin-Walled Structures 131: 192-204.

Liu, K. G., L., 2006 Thermal buckling of heat-exposed axially restrained composite column. Composites part A 37: 972-980.

Mourão, S. V., H., 2007 On the behaviour of single-span steel beams under uniform heating. J Braz Soc Mech Sci Eng 29: 115-122.

Nayfeh, M. D., A., 1979 Nonlinear Oscillations. New York (N.Y.) : Wiley.

Ndoukouo, N. A. W. P., A., 2011 On the dynamics of fire-exposed steel beam under mechanical load. Journal of Constructional Steel Research 67: 1864-1871.

Nubissie, N. A. . W. P., A., 2011 Dynamical behavior of a wooden beam under mechanical loading and fire. Materials and Design 32: 1331-1336.

Ribeiro, M. E., P., 2005 The effect of temperature on the large amplitude vibrations of curved beams. Journal of Sound and Vibration. 285: 1093-1107.

Rotter, A., J.; Usmani, 2000 Fundamental principles of structural behaviour under thermal effects. In Proceedings First International Workshop on the Performance of Structures in Fire, Copenhagen.

Seputro, J., 2001 Effect of Support Conditions on Steel Beams Exposed to Fire. phdthesis, School of Engineering, University of Canterbury: New Zealand.

Timoshenko, J., S.; Gere, 1951 Theory of elastic stability.
Yaobing, C. H., Z., 2018 Temperature effects on nonlinear vibration behaviors of euler-bernoulli beams with different boundary conditions. Shock and Vibration 6: 1-11.

How to cite this article: Ndoukouo, A. N., Metsebo, J., and Njankouo, J. M. Vibrational analysis of a metallic column submitted to mechanical axial load and fire exposure. Chaos Theory and Applications, 3(2), 77-86, 2021. 